\title{
Pengembangan Teknologi Purifikasi Biogas (Kandungan Gas H2S Dan CO2) dengan Mempergunakan Kombinasi Wet Scrubber-Batu Gamping
}

\author{
Totok Soehartanto, Sarwono, \& Ronny Dwi Noryati \\ 1Fakultas Teknologi Industri, Jurusan Teknik Fisika, Institut Teknologi sepuluh Nopember 2 Fakultas \\ Teknologi Industri, Jurusan Teknik Fisika, Institut Teknologi sepuluh Nopember*totokstf@yahoo.com
}

\begin{abstract}
Abstrak
Biogas yang diproduksi dari hasil fermentasi kotoran ternak melalui bioreactor anaerob $60 \%-70 \%$ berupa gas methane $\left(\mathrm{CH}_{4}\right)$, sekitar $30 \%$ berupa gas $\mathrm{CO}_{2}$ dan sisanya berupa gas $\mathrm{H}_{2} \mathrm{~S}$ serta gas-gas lainnya. $\mathrm{Gas} \mathrm{CO}_{2}$ jika terbakar berdampak terhadap lingkungan (hujan asam), sedang gas $\mathrm{H}_{2} \mathrm{~S}$ bersifat korosif. Sehingga biogas hasil ekstraksi kotoran ternak perlu dipurifikasi agar ramah terhadap lingkungan dan aman buat peralatan (kompor gas). Metode pemurnian mempergunakan kombinasi water scrubber dan batu gamping, hal ini dikarenakan water scrubber efektif untuk mengurangi gas $\mathrm{H}_{2} \mathrm{~S}$ sedang batu gamping efektif untuk menyerap gas $\mathrm{CO}_{2}$. Metode kombinasi ini telah diterapkan untuk pemurnian biogas hasil ekstraksi biogas dari kotoran ternak di kelompok peternak sapi di Nongko Jajar, dimana warna api yang dihasilkan dari pembakaran biogas hasil purifikasi biru sedang warna api biogas yang tidak dimurnikan bercampur dengan warna merah. Disamping itu air yang keluar dari water scrubber berbau belerang dan warna batu gamping berubah menjadi kuning. Sehingga pada makalah ini dipresentasikan design pengembangan filter purifikasi biogas, dalam hal ini water tidak lagi di spray-kan akan tetapi dirubah dalam bentuk kabut untuk mengefektifkan kontak antara biogas dengan kabut. Filter batu kapur berjumlah 2 buah, akibat batu gamping akan mengalami kejenuhan setelah dipergunakan dalam interval waktu tertentu.
\end{abstract}

Kata kunci: biogas, purifikasi, water scrubber, batu gamping.

\section{PENDAHULUAN}

Biogas dihasilkan dari proses anaerobik dan terdiri dari unsur utama berupa metana $\left(\mathrm{CH}_{4}\right)$ dan karbon dioksida $\left(\mathrm{CO}_{2}\right)$, dan beberapa unsur yang lain, seperti hidrogen sulfida $\left(\mathrm{H}_{2} \mathrm{~S}\right)$, amonia $\left(\mathrm{NH}_{3}\right)$, hidrogen $\left(\mathrm{H}_{2}\right)$, nitrogen $\left(\mathrm{N}_{2}\right)$, karbon monoksida (CO) , jenuh atau terhalogenasi karbohidrat, dan oksigen $\left(\mathrm{O}_{2}\right)$. Biogas dapat juga mengandung partikel debu dan siloksan [1]. Komposisi biogas yang dihasilkan dari pencernaan anaerobik biasanya sekitar $60-70 \% \mathrm{CH}_{4}$, sekitar $30-40 \% \mathrm{CO}_{2}$, kurang dari $1 \% \mathrm{~N}_{2}$, dan sekitar 10 - 2000 ppm $\mathrm{H}_{2} \mathrm{~S}$ (Osorio \& Torres, 2009 ). Biogas memiliki nilai kalor (HHV) antara 15 dan 30 $\mathrm{MJ} / \mathrm{Nm}^{3}[2]$, sehingga dapat langsung digunakan untuk proses pembakaran.

Besarnya kadar gas pengotor berupa air, $\mathrm{CO}_{2}$ dan $\mathrm{H}_{2} \mathrm{~S}$ yang memiliki prosentase berbeda dimungkinkan dapat terjadi karena jenis makanan yang dikonsumsi oleh ternak dan efektivitas sistem biodigestif yang berlangsung dalam reaktor (Watanabe, 2006). Gas metana merupakan unsur primer dan menjadi parameter utama dalam menentukan kualitas hasil produksi pengolahan biogas. Hal ini karena energi yang ada dalam biogas bergantung dari konsentrasi gas metana $\left(\mathrm{CH}_{4}\right)$. Semakin tinggi kandungan gas metana, maka semakin besar kandungan energi kalor pada biogas, begitu pula sebaliknya

Kualitas biogas dapat ditingkatkan dengan beberapa perlakuan, yaitu dengan menghilangkan gas-gas pengotor pada biogas, terutama mereduksi kadar hidrogen sulfur $\left(\mathrm{H}_{2} \mathrm{~S}\right)$ dan karbondioksida $\left(\mathrm{CO}_{2}\right)$, serta Particulate Matter $(\mathrm{PM})$. Hal ini didasarkan pada beberapa hal, antara lain hidrogen sulfur mengandung racun dan zat yang menyebabkan korosi. Jika biogas mengandung senyawa ini, maka akan menimbulkan gas yang berbahaya, sehingga pada beberapa literatur yang ada, kadar yang diijinkan maksimal 5 ppm. Jika biogas dibakar, kandungan hidrogen sulfur lebih berbahaya karena akan membentuk senyawa baru bersama oksigen, berupa sulfur dioksida $\left(\mathrm{SO}_{2}\right)$ atau sulfur trioksida $\left(\mathrm{SO}_{3}\right)$. Kedua senyawa ini lebih beracun daripada $\mathrm{H}_{2} \mathrm{~S}$. Apabila proses pembakaran yang mengandung $\mathrm{H}_{2} \mathrm{~S}$ terus dilanjutkan, maka akan terbentuk sulfur acid $\left(\mathrm{H}_{2} \mathrm{SO}_{3}\right)$ yang bersifat lebih korosif daripada $\mathrm{H}_{2} \mathrm{~S}$. Pembakaran gas yang masih mengandung $\mathrm{H}_{2} \mathrm{~S}$ juga akan menghasilkan senyawa asam $\left(\mathrm{H}_{2} \mathrm{SO}_{4}\right)$. Senyawa ini dapat menimbulkan kerugian besar karena bersifat korosif. Di samping itu hujan asam yang terjadi akibat kontaminasi senyawa ini pun dapat mencemari lingkungan hidup. Sedangkan karbondioksida $\left(\mathrm{CO}_{2}\right)$ memiliki sifat yang dapat menghambat proses pembakaran yang sempurna, beracun, dan dapat menyebabkan korosi. Untuk PM yang terkandung di dalam biogas dapat menyebabkan terhambatnya biogas dalam proses pembakaran, serta berbahaya bagi pernafasan manusia untuk PM dengan ukuran 2,5 - $10 \mu \mathrm{m}$. 
Ada banyak cara untuk mengurangi kandungan gas $\mathrm{H}_{2} \mathrm{~S}$, salah satunya mempergunakan metode kontak dengan air atau yang lazim disebut dengan metode water scrubber dan untuk menghilangkan kandungan gas $\mathrm{CO}_{2}$ dapat mempergunakan filter batu kapur (batu gamping). Makalah ini akan mempresentasikan rancangan filter purifikasi biogas dengan mempergunakan kombinasi water scrubber dan filter batu gamping $(\mathrm{NaOCl})$.

\section{TINJAUAN PUSTAKA}

\section{Biogas sebagai Produk Digestifikasi Anaerob}

Biogas adalah campuran gas mudah terbakar yang dihasilkan oleh bakteri metanogenik yang terjadi pada materialmaterial yang dapat terurai secara alami dalam kondisi anaerobik. Pada umumnya biogas terdiri atas gas metana $\left(\mathrm{CH}_{4}\right)$, gas karbon dioksida $\left(\mathrm{CO}_{2}\right)$, Hidrogen $\left(\mathrm{H}_{2}\right)$ dan gas-gas lainnya dalam jumlah yang sedikit. Biogas kira-kira memiliki berat 20 persen lebih ringan dibandingkan udara dan memiliki suhu pembakaran antara 650 sampai $750{ }^{\circ} \mathrm{C}$. Biogas tidak berbau dan berwarna yang apabila dibakar akan menghasilkan nyala api biru cerah seperti gas LPG. Nilai kalor gas metana adalah 20 $\mathrm{MJ} / \mathrm{m}^{3}$ dengan efisiensi pembakaran 60 persen pada konvesional kompor biogas. Gas metana merupakan produk utama dari biogas. Kualitas biogas bergantung pada besarnya nilai gas ini.

\section{Gas $\mathrm{H}_{2} \mathrm{~S}$}

Gas $\mathrm{H}_{2} \mathrm{~S}$ adalah gas Hidrogen Sulfida yang terbentuk dari 2 unsur Hidrogen dan 1 unsur Sulfur. Satuan ukur gas $\mathrm{H}_{2} \mathrm{~S}$ adalah ppm (part per milion). Gas $\mathrm{H}_{2} \mathrm{~S}$ disebut juga gas telur busuk, gas asam, asam belerang atau uap bau. Hidrogen sulfida $\left(\mathrm{H}_{2} \mathrm{~S}\right)$ merupakan gas yang tidak berwarna, beracun, mudah terbakar dan berbau. Gas ini dapat membahayakan bagi kesehatan manusia jika terhirup dalam ambang batas konsentrasi tertentu. Peraturan Menteri Kesehatan (Permenkes) No 416/Menkes/PER/IX/1990 menyatakan bahwa batas maksimum konsentrasi gas hidrogen sulfida pada air minum yang diizinkan hanya $0,05 \mathrm{mg} /$ liter. Sedangkan untuk kadar $\mathrm{H}_{2} \mathrm{~S}$ dalam produk gas, nilai yang diijinkan adalah maksimum sebesar 5 ppm.

Menurut Lastella et al (2002), konsentrasi gas ini dalam biogas relatif kecil $\pm 0,1-2 \%$. Namun gas ini bersifat korosif sehingga konsentrasi yang kecil maupun besar dalam biogas dapat menyebabkan korosi pada ruang pembakaran. Selain itu, gas ini mempunyai bau yang tidak sedap, bersifat racun dan hasil pembakarannya menghasilkan gas sulfur dioksida $\left(\mathrm{SO}_{2}\right)$.

\section{Gas $\mathrm{CO}_{2}$}

Gas $\mathrm{CO}_{2}$ dalam biogas perlu dihilangkan karena gas tersebut dapat mengurangi nilai kalor pembakaran biogas. Nilai kalor pembakaran gas metana murni pada tekanan $1 \mathrm{~atm}$ dan temperatur $15,5^{\circ} \mathrm{C}$ yaitu $9100 \mathrm{Kkal} / \mathrm{m}^{3}(12.740 \mathrm{Kkal} / \mathrm{kg})$. Sedangkan nilai kalor pembakaran biogas sekitar $4.800-6.900 \mathrm{Kkal} / \mathrm{m}^{3}(6.720-9660 \mathrm{Kkal} / \mathrm{kg})$ (Harasimowicz et al, 2007). Tingginya kandungan $\mathrm{CO}_{2}$ dalam biogas menyebabkan nilai kalor pembakaran turun menjadi sebesar 4.301,63 - 6.213,47 Kkal/m $(6.022,28-8.698,85 \mathrm{Kkal} / \mathrm{kg})$ dari nilai pembakaran CH4 murni sebasar 9.559,18 Kkal/m³ $(13.382,85 \mathrm{Kkal} / \mathrm{kg})$.

\section{Proses Pemurnian Biogas}

Biogas akan memiliki karakteristik yang sama dengan gas alam alam atau LNG apabila biogas dibersihkan dari pengotor secara optimal. Komponen pengotor dalam biogas berupa $\mathrm{H}_{2} \mathrm{O}, \mathrm{H}_{2} \mathrm{~S}, \mathrm{CO}_{2}$, dan partikulat harus dihilangkan untuk mencapai kualitas gas yang lebih baik. Secara teknis pemakaian biogas yang belum mengalami pemurnian biasanya dicampur dengan gas alam untuk meningkatkan pembakaran .

Tabel. 1. Efek Komponen Pengotor di Dalam Biogas (Sumber : Noyola, et. al., 2006)

\begin{tabular}{|c|c|c|}
\hline Komponen & Persentase & Efek \\
\hline $\mathrm{CO}_{2}$ & $25-50 \%$ & $\begin{array}{l}\text { - Mengurangi nilai panas pembakaran } \\
\text { - Menyebabkan korosi (kandungan asam carbon) jika gas cukup } \\
\text { basah } \\
\text { - Meningkatkan knocking pada mesin }\end{array}$ \\
\hline $\mathrm{H}_{2} \mathrm{~S}$ & $0-0,5 \%$ & $\begin{array}{l}\text { - Menyebabkan korosi pada peralatan dan sistem pemipaan } \\
\text { - Menyebabkan emisi } \mathrm{SO}_{2} \\
\text { - Merusak katalis }\end{array}$ \\
\hline $\mathrm{NH}_{3}$ & $0-0,05 \%$ & $\begin{array}{l}\text { - Emisi NOx setelah pembakaran } \\
\text { - Meningkatkan knocking pada mesin }\end{array}$ \\
\hline Uap air & $1-5 \%$ & - Menyebabkan korosi pada peralatan dan sistem pemipaan \\
\hline Debu & $>5 \mu \mathrm{m}$ & - Menutup nozle \\
\hline
\end{tabular}




\section{Metode Penelitian}

Pengukuran komposisi gas yang dikandung Biogas

Perancangan Filter Purifikasi Biogas untuk menghilangkan gas $\mathrm{CO}_{2}$ dan gas $\mathrm{H}_{2} \mathrm{~S}$

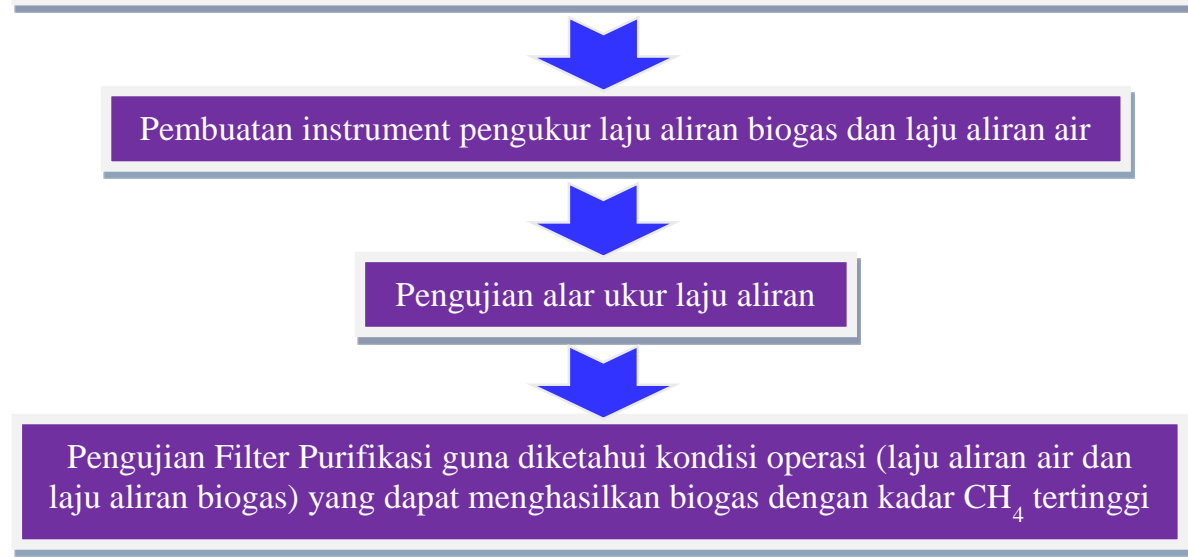

Gambar. 1. Diagram alir penelitian

Filter purifikasi fase satu dengan mempergunakan kombinasi water scrubber dan batu gamping, dimana air di spay ke dalam tabung dengan mempergunakan pompa agar dapat kontak dengan biogas yang dialirkan dari posisi tengah tabung.

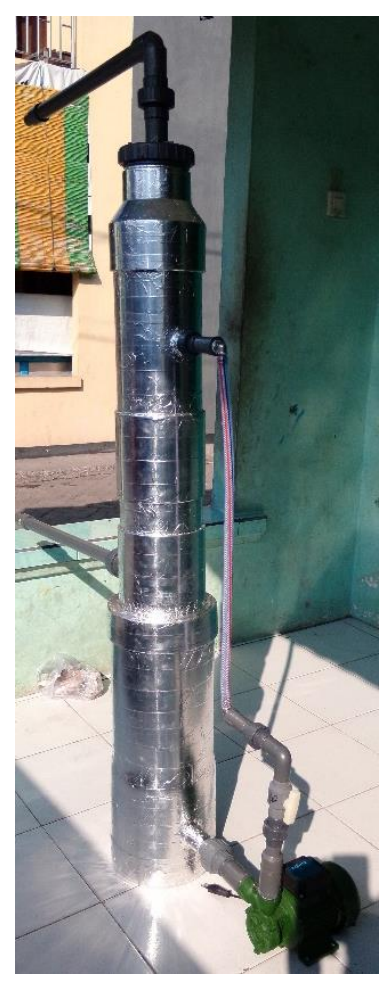

Gambar. 2. Prototype filter purifikasi generasi satu (kombinasi water scrubber dan batu gamping)

Filter generasi dua, merupakan pengembangan dari filter purifikasi generasi satu, dimana pada generasi dua tidak mempergunakan air yang di spray kan melainkan air dirubah dalam bentuk kabut untuk meningkatkan efektifitas bidang kontak (antara biogas dan uap air berbentuk kabut). 

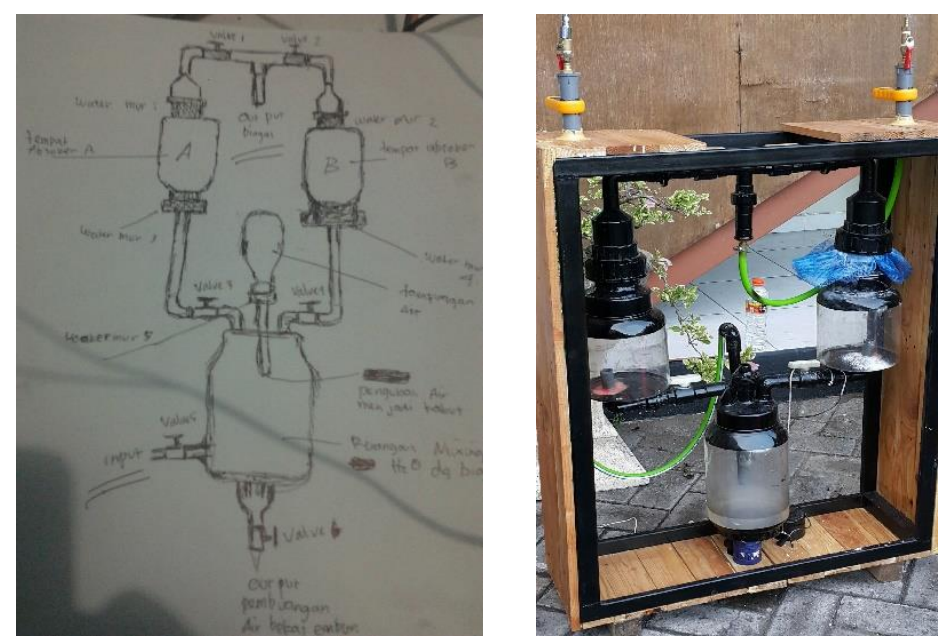

Gambar. 2. Design Filter purifikasi Biogas generasi kedua dan Prototype Filter purifikasi Biogas generasi kedua

\section{Hasil dan Pembahasan}

Pengujian filter generasi pertama menunjukkan bahwa air yang dipergunakan sebagai absorber berbau belerang setelah keluar dari tabung water scrubber, serta warna air menjadi keruh. Biogas hasil filterisasi jika dibakar mempunyai warna api biru.
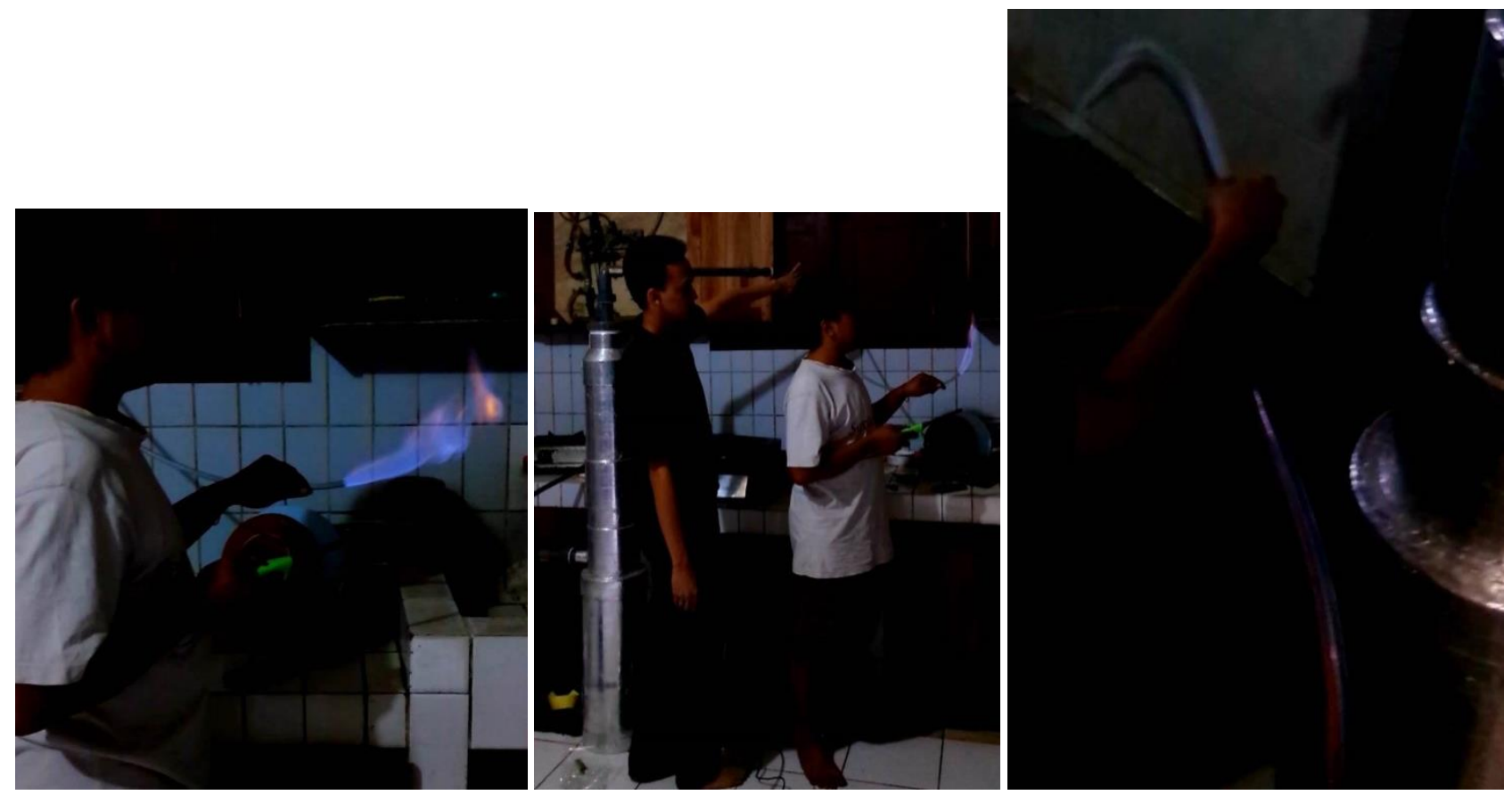

Gambar. 3. Warna api hasil pembakaran biogas hasil purifikasi dan air outlet water scrubber

Filter purifikasi generasi satu ini membutuhkan pompa air dan filter batu gamping jika mengalami kejenuhan, harus diganti dengan cara membongkar filter purifikasi, untuk itu pada generasi kedua water scrubber tidak mempergunakan air yang dispraykan melalui pompa air, akan tetapi mempergunakan sistem pengkabutan air. Filter batu gamping dibuat redundence, dalam arti jika filter mangalami kejenuhan, dapat di switch ke filter lainnya tanpa harus menghentikan proses purifikasi. Untuk mengetahui kinerja filter purifikasi generasi kedua, maka dilakukan pengukuran komposisi biogas.

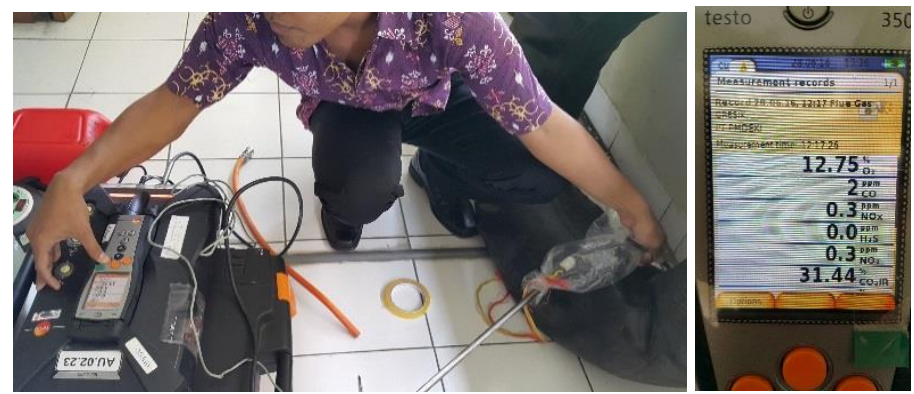

Gambar. 4. Pengukuran komposisi biogas sebelum di filter 
Dari hasil pengukuran Nampak bahwa Biogas yang diambil dari ICCR (Indonesia Cocoa and Coffee Research) Jember kandungan gas $\mathrm{H}_{2} \mathrm{~S}$ sangat rendah, akan tetapi kandungan gas $\mathrm{CO}_{2}$ nya cukup tinggi mencapai 31,44\%. Untuk mengurangi kadar gas $\mathrm{CO}_{2}$ dilakukan dengan mempergunakan Filter Purifikasi generasi kedua seperti ditunjukkan pada gambar 5.
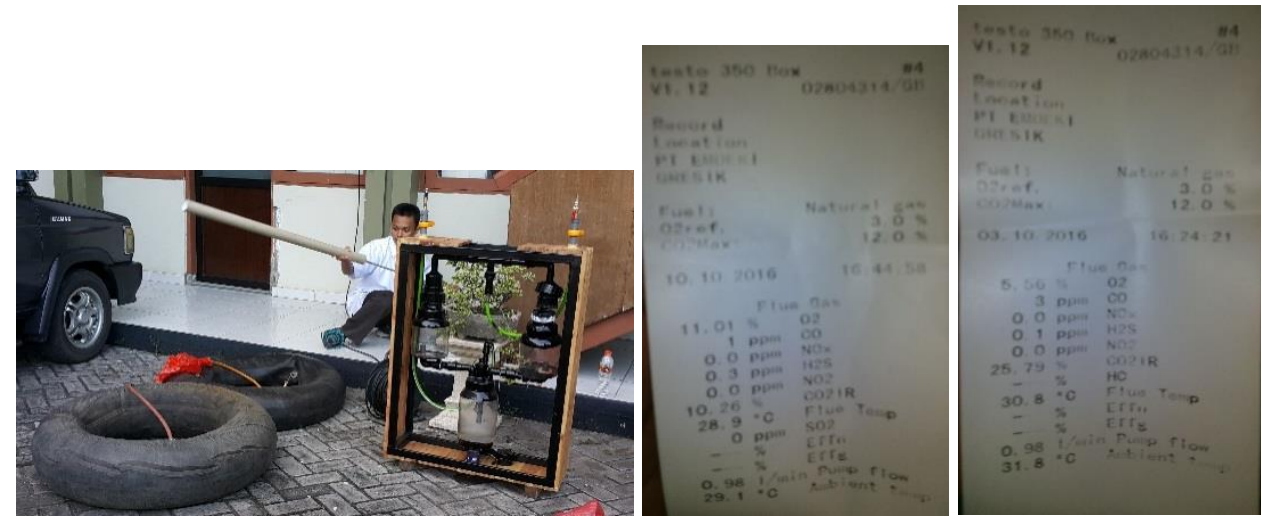

Gambar. 5. Pengukuran komposisi biogas dengan mempergunakan Filter purifikasi generasi kedua

Dari hasil pengukuran menunjukkan bahwa sebelum di filter kadar gas $\mathrm{CO}_{2}$ 25,79\% dan setelah di filter turun menjadi $10,26 \%$, sedang kadar gas $\mathrm{H}_{2} \mathrm{~S}$ nya naik malah naik dari $0.1 \mathrm{ppm}$ menjadi $0.3 \mathrm{ppm}$ (hal ini dikarenakan proses pengukuran dilakukan ketika tabung mengkabutan belum terisi sepenuhnya dengan kabut air).

\section{Kesimpulan}

- Telah dilakukan pengembangan Filter Purifikasi Biogas dengan mempergunakan kombinasi Water Scrubber dan filter batu gamping berjumlah 2 buah guna menjaga kontinuitas proses pemfilteran.

- Water scrubber dengan mempergunakan kabut air untuk meningkatkan bidang kontak biogas dengan air

- $\quad$ Filter batu gamping berjumlah 2 buah, satu berfungsi sebagai redundancies (jika filter yang dipergunakan mengalami kejenuhan) dapat dilakukan switching.

- Dari hasil implementasi menunjukkan bahwa filter batu gamping efektif untuk menurunkan kadar gas $\mathrm{CO}_{2}$ yang dikandung biogas.

\section{DAFTAR PUSTAKA}

[1] P. Wheeler, T. Jaatinen, A. Lindberg, J. B. Holm-Nielsen, A. Wellinger, and A. Pettigrew, Biogas Upgrading and Utilisation. Paris: International Energy Association, 2000.

[2] N. Abatzoglou and S. Boivin, “A review of biogas purification processes," Biofuels, Bioprod. Biorefining, vol. 3, no. 1, pp. 42-71, Jan. 2009. 